\title{
Hypothermia-induced retrograde amnesia: Role of body temperature in memory retrieval
}

\author{
CHARLES F. MACTUTUS and DAVID C. RICCIO \\ Kent State University, Kent State, Ohio 44242
}

\begin{abstract}
The relationship of body temperature to the onset, and the subsequent alleviation, of hypothermia-induced retrograde amnesia (RA) was investigated. In Experiment 1, the retention of a passive avoidance task and the body temperature at the time of testing were assessed at intervals of $4,8,12$, and $16 \mathrm{~h}$ after training/amnesic treatment. While retention was evident for up to $12 \mathrm{~h}$ posthypothermia treatment, it was clear that body temperature did not index magnitude of RA. A second experiment examined the alleviation of hypothermiainduced RA as a function of body temperature and retention interval. Memory recovery was facilitated at both 1- and 7-day intervals when testing occurred at $29^{\circ}-31^{\circ} \mathrm{C}$ but not at $33^{\circ}-35^{\circ} \mathrm{C}$. The possibility of different mechanisms underlying retention after hypothermia and retrieval after recooling was suggested. An alternative explanation in terms of contextual cues and cue utilization was also discussed.
\end{abstract}

Administration of an agent such as electroconvulsive shock (ECS) or hypothermia shortly after passive avoidance training is a well-established paradigm to produce retrograde amnesia (RA). Generally, this experimentally induced RA has been measured $24 \mathrm{~h}$ after the training/amnesic treatment session. Recently, however, a few studies have examined the magnitude of retention loss at intervals less than $24 \mathrm{~h}$. With ECS, the evidence indicates a delay in the onset of RA ranging from 15 min (Miller \& Springer, 1971) to $6 \mathrm{~h}$ (Geller \& Jarvik, 1968b). Other studies consistent with this observation of retention for several hours after ECS treatment have been reported (McGaugh \& Landfield, 1970; Zerbolio, 1971).

With hypothermia as the amnesic agent, there has been no attempt to trace the onset of RA, although intervals less than $24 \mathrm{~h}$ have been examined. Misanin, Nagy, Keiser, and Bowen (1971) found RA 24 h after hypothermia treatment, but not at $1 \mathrm{~h}$, for 9 day old rats. This finding was extended (Hinderliter, Webster, \& Riccio, 1975) to include adult rats (90-120 days). Interestingly, in their Experiment I, Hinderliter et al. found little RA $4 \mathrm{~h}$ after hypothermia treatment, a time at which rats still had a mean body temperature of only $28.5^{\circ} \mathrm{C}$; in contrast, typical

This paper is based on a thesis submitted by the first author in partial fulfillment of the requirements for the master's degree at Kent State University. This investigation was supported in part by National Institute of Mental Health Grant MH30223-01 to the second author. We acknowledge the constructive comments of Drs. B. H. Newberry, F. R. Treichler, and J. S. Myer. Requests for reprints should be addressed to David C. Riccio, Psychology Department, Kent State University, Kent, Ohio 44242. memory loss was observed at a 24 -h test interval when subjects had returned to normal body temperature levels. These data suggested that the continued presence of the "cold state cues" might permit access to the target memory. The importance of cold cues seemed borne out by evidence that recooling alleviated amnesia, and that this effect was transient. However, the investigators also noted (Experiment II) that $6 \mathrm{~h}$ after training/amnesic treatment there was little, if any, amnesia despite the near normal body temperatures $\left(>36.0^{\circ} \mathrm{C}\right)$ of the animals. The primary aim of the present study was to examine systematically the onset of hypothermia-induced RA in a passive avoidance situation with retention tests at various intervals after the training/amnesic treatment session, and to assess the possibility that the retention observed after the hypothermia treatment might be temperature dependent.

\section{EXPERIMENT 1}

Experiment 1 measured body temperature and retention of a passive avoidance task at intervals of 4 , 8,12 , and $16 \mathrm{~h}$ after training/amnesic treatment.

\section{Method}

Subjects. Forty-eight adult male Holtzman albino rats (305$420 \mathrm{~g}$ ) served as subjects. The animals were housed in the colony for at least 1 week prior to the start of the experiment. The colony was maintained on a 16-h light/8-h dark cycle, with the room temperature at $20^{\circ}-22^{\circ} \mathrm{C}$. Throughout the study, food and water were provided ad lib.

Apparatus. The training apparatus consisted of a passive avoidance (PA) chamber $(45.5 \times 17.5 \times 23.5 \mathrm{~cm})$ constructed of Plexiglas and aluminum. The chamber was divided into two equal- 
sized compartments by a partition with a $6.5 \times 9.0 \mathrm{~cm}$ opening which could be blocked by lowering a door. While one compartment had white walls and a clear Plexiglas lid, the second compartment had both black walls and a black lid. The flooring was identical in both compartments, with $.20 \mathrm{~cm}$ grids spaced $1.0 \mathrm{~cm}$ apart, but only the grids on the black side were connected to a scrambled shock source. A $150-\mathrm{V}$ shock from a matchedimpedance shock source (Campbell \& Techtsoonian, 1958) was delivered via a Foringer Model SC-901 scrambler. A removable unpainted plywood compartment with a clear Plexiglas lid was fitted inside the black compartment to administer noncontingent footshock. The experimental room for the PA apparatus was illuminated by a $15-\mathrm{W}$ light bulb suspended $30 \mathrm{~cm}$ above the center of the white compartment. Standard electromechanical equipment was used to monitor each animal's cross-through latency to the nearest 10th of a second. Hypothermia was produced using a Model 1095 Forma Temp Jr. bath water and circulator, maintained at $3^{\circ}-5^{\circ} \mathrm{C}$. Wire cloth tubes were used to restrain subjects during the cooling immersion periods. A Yellow Springs Tele-Thermometer, Model 43 TD, was employed along with a rectal probe to record body temperature.

Procedure. Four days prior to training, all animals were weighed, ear punched for purposes of identification, and individually caged. On each of 3 subsequent days, every animal was handled for a 5-min period.

On the training day, each of 40 randomly selected animals was placed in the white compartment facing away from the door separating the two chambers. Ten seconds later, the door was raised and the time taken for the animal to cross through into the black side (all four feet) was recorded to the nearest 10th of a second. All 40 rats received a $1-\mathrm{sec} 150-\mathrm{V}$ inescapable footshock immediately after crossing into the black side. Training for the remaining 8 rats consisted of a noncontingent footshock (NCFS) within $10 \mathrm{sec}$ after being placed in the black side with the plywood insert installed.

The treatment phase followed immediately after training. Each of 32 PA trained rats was randomly assigned to one of four experimental amnesia groups (FS-HYPO). The groups were differentiated by subsequent assignment to treatment-test intervals of $4,8,12$, and $16 \mathrm{~h}$. All animals assigned to the FS-HYPO groups were restrained in the wire cloth tubes $30-45 \mathrm{sec}$ after receiving footshock and immersed in $3^{\circ}-5^{\circ} \mathrm{C}$ water. If, after $10 \mathrm{~min}$, body temperature was not $21.0^{\circ} \mathrm{C}$ or below, the animals were reimmersed for $30-\mathrm{sec}$ periods until this criterion was met. Body temperature was assessed by insertion of a rectal probe $3.2 \mathrm{~cm}$ into the rat's anus. The animals were then removed from the wire cloth tubes, wiped with paper and cloth towels to remove excess water, and then returned to their home cages. The remaining 8 animals which were given PA training were assigned to the retention control group (FS-No HYPO) and were returned to their home cages in the colony immediately after removal from the PA apparatus. The 8 animals administered NCFS in the training phase were given hypothermia treatment identical to that of the experimental amnesia animals. None of the subjects in this performance control group (NCFS-HYPO) were actually exposed to the whiteblack PA apparatus until testing.

The testing procedure was similar to the training procedure, except that no shock was administered. All FS-HYPO subjects were tested at their specified interval. The NCFS-HYPO animals were tested at the short 4-h interval to control for the possible systemic and/or motor debilitating effects inherent in the experimental procedure. The FS-No HYPO control group was tested at $72 \mathrm{~h}$ posthypothermia, yielding a conservative estimate of retention of the PA training. Those subjects not crossing within $15 \mathrm{~min}$ were assigned a test latency of $900 \mathrm{sec}$ and were removed from the apparatus. To obtain a second measure of retention, all animals remained in the PA apparatus for the full 15-min session and their preference for the white (safe) side was also monitored. Immediately after testing, the rectal temperature of each animal was recorded.

\section{Results and Discussion}

Prior to the shock punishment, the mean crossthrough latencies for the retention control, 4-, 8-, 12-, and 16-h FS-HYPO groups were 40.1, 45.0, $36.3,30.8$, and $15.7 \mathrm{sec}$, respectively. Although these initial latencies are slightly longer than we typically obtain, a one-way analysis of variance indicated no significant differences among the groups $(F=.64$, df $=4 / 35, p>.10)$. Thus, whatever contributed to the elevated response tendency did not appear to introduce any systematic bias.

Figure 1 presents the test latency data as a function of the interval between training/amnesic treatment and testing. Nonparametric two-tailed statistics were performed on all the test data, unless otherwise stated, because of the large number of ceiling scores. Significant treatment effects were demonstrated with a Kruskal-Wallis one-way analysis of variance on both the latency $(\mathrm{H}=14.64, \mathrm{df}=5, \mathrm{p}<.02)$ and preference $(\mathrm{H}=14.66, \mathrm{df}=5, \mathrm{p}<.02)$ measures. Since more detailed analyses yielded the same pattern of results on the two dependent variables, only the latency results are reported. Subsequent MannWhitney $U$ tests revealed that the latencies of the 4-, 8-, and 12-h FS-HYPO groups were comparable to those of the retention control animals (Us $>24$ ), while the 16-h FS-HYPO latencies were significantly depressed $(U=16, p<.05$, one-tailed). The good retention scores of the FS-HYPO groups tested at the shorter intervals may not be attributed to any systemic or motor debilitating effect of the experimental treatments as the NCFS-HYPO group displayed crossthrough latencies significantly faster than the experimental animals tested after an identical time interval $(\mathrm{U}=5, \mathrm{p}<.001)$.

Wilcoxin matched-pairs signed-ranks analyses indicated that the test latencies were reliably longer than the training latencies for all groups (Ts $<1$, $\mathrm{p}<.02)$, except the 16-h FS-HYPO animals $(T=11$,

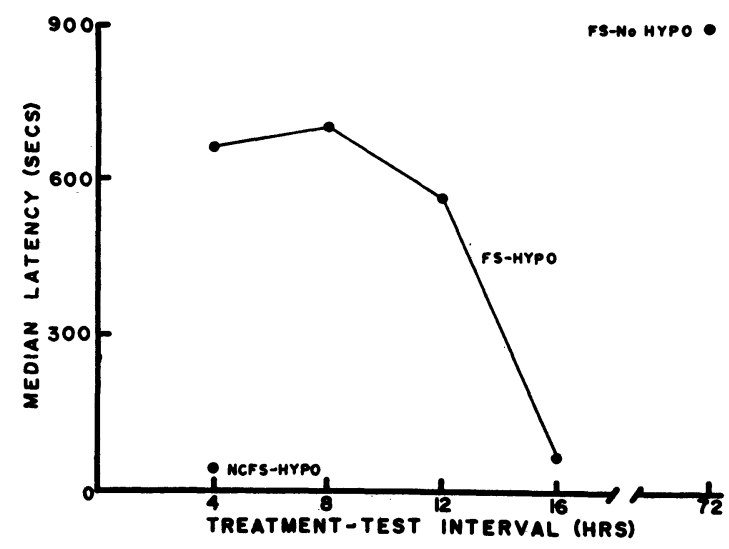

Figure 1. Median latency at testing as a function of treatmenttest interval. 
$\mathrm{p}>.10$ ), providing further evidence that these latter animals were amnesic.

Among the FS-HYPO groups, only the 4-h:16-h and 8-h:16-h comparisons were significant (Us $=16$, $\mathrm{p}<.05$, one-tailed).

Mean rectal temperatures taken immediately after testing ranged between $37.1^{\circ}$ and $37.7^{\circ} \mathrm{C}$ for all groups. A one-way analysis of variance indicated that, irrespective of the interval between training/ amnesic treatment and testing, the temperatures of all groups were similar $(\mathrm{F}=1.28, \mathrm{df}=5 / 42$, $\mathrm{p}>.10)$.

\section{EXPERIMENT 2}

A good deal of literature has been reviewed which suggests that experimentally induced memory deficits may be alleviated by a reactivation treatment (Miller \& Springer, 1973; Spear, 1973). Recently, Hinderliter et al. (1975) found evidence for attenuation of hypothermia-induced RA when animals were given a retention test $2 \mathrm{~h}$ after a recooling treatment, but not at 4,24 , or $72 \mathrm{~h}$. In contrast, recovery of memory from ECS-induced RA was stable over a retention interval of at least 5 days with NCFS as the reminder treatment (Miller \& Springer, 1972a). Interestingly, Hinderliter et al. reported that their experimental groups which displayed memory recovery after recooling were at body temperatures of $29.6^{\circ}$ and $32.1^{\circ} \mathrm{C}$. Unfortunately, no body temperatures were given for the tests 4,24 , and $72 \mathrm{~h}$ after recooling where the memory was not reactivated. A possible temperature-dependent recovery of memory would be of marked interest considering the results of Experiment 1 , where good retention was found for $12 \mathrm{~h}$ after hypothermia although body temperatures had returned to normal by $4 \mathrm{~h}$. Pilot data indicated substantial variability in recovery from recooling when assessed at a specific temporal interval. Accordingly, the major purpose of Experiment 2 was to replicate the recooling study with an attempt to establish a more precise relationship between recovery of memory and body temperature at time of testing.

An additional finding of the Hinderliter et al. (1975) study indicated that the recooling treatment was effective in reactivating memory at 24 and $48 \mathrm{~h}$ posttraining/amnesic treatment. The effectiveness at longer intervals was not examined. Evidence with ECS-induced RA has shown that a noncontingent foot shock may serve as a sufficient reminder treatment even when delayed for as long as 2 weeks (Miller \& Springer, 1972a). A second aim here was to determine if memory recovery after hypothermiainduced RA is possible after a retention interval con-. siderably longer than $48 \mathrm{~h}$. An earlier study from our lab found no evidence of spontaneous recovery from this type of amnesia with a 10-day test delay (Riccio \& Stikes, 1969).
The present experiment examined the effectiveness of a recooling treatment at intervals of 1 and 7 days posttraining/amnesic treatment. Retention was assessed upon return of body temperature to either $29^{\circ}-31^{\circ} \mathrm{C}$ (cold) or $33^{\circ}-35^{\circ} \mathrm{C}$ (cool).

\section{Method}

Subjects. Sixty-four adult Holtzman albino male rats, weighing between $283-468 \mathrm{~g}$, served as subjects. Prior to experimental manipulations, all rats were treated as in Experiment 1.

Apparatus. The same apparatus used in Experiment 1 was employed in Experiment 2.

Procedure. Thirty-six animals were randomly chosen for the experimental manipulations and were divided among four groups $(\mathrm{ns}=9)$. These animals received one-trial passive avoidance (PA) training and subsequent hypothermia. The specific details of the PA and hypothermia procedures were as previously stated. Two groups were randomly assigned to a 1-day retention condition, and two groups to a 7-day retention condition. At the end of the retention interval, all four groups were recooled to $25.0^{\circ} \mathrm{C}$ and allowed to rewarm. For both 1- and 7-day conditions, testing occurred when the animals' body temperatures returned to either $29^{\circ}-31^{\circ} \mathrm{C}$ or $33^{\circ}-35^{\circ} \mathrm{C}$. A rewarming cutoff of $2.5 \mathrm{~h}$ was set such that all animals were tested during the same period of the day. Specific testing procedures were identical to those of Experiment 1.

The 28 remaining animals were randomly assigned to three control conditions. The performance control group (NCFS-HYPO$\mathrm{R}-1-30^{\circ} \mathrm{C}, \mathrm{n}=9$ ) received noncontingent footshock in training, followed immediately by hypothermia and subsequent recooling to $25.0^{\circ} \mathrm{C}$ after 1 day; the retention control group (FS-No HYPO-No Recool, $n=9)$ received PA training only; and the amnesic controls (FS-HYPO-No Recool, $n=10$ ) were treated identically to the experimental animals but were not recooled. Testing occurred upon return of body temperature to $29^{\circ}-31^{\circ} \mathrm{C}$ for the performance controls, and at a comparable interval $(25.75 \mathrm{~h})$ for the retention and amnesic controls. Retention was indexed by measures of crossthrough latency (600-sec ceiling) and preference for the white compartment.

The subjects were run in several replications with an attempt to obtain data for each group from more than one replication. Although four subjects died and one was discarded due to equipment failure, they were not replaced. Within an 8-week period, all subjects had been run.

\section{Results and Discussion}

Mean training latencies were $12.0,13.9,11.6$, and $4.1 \mathrm{sec}$ for the experimental groups, and 3.8 and $15.0 \mathrm{sec}$ for the amnesic and retention control groups. A one-way analysis of variance showed no significant differences among the training latencies $(F=1.34$, $\mathrm{df}=5 / 45, \mathrm{p}>.10$ ), indicating that prior to the experimental manipulations all groups performed similarly on the PA task.

The test latency data, shown in Figure 2, are plotted as a function of retention interval. A significant effect of the experimental manipulations was indicated by a Kruskal-Wallis one-way analysis of variance of the test latencies $(\mathrm{H}=22.25$, df $=6$, $\mathrm{p}<.001)$ and of the preference measure $(\mathrm{H}=28.07$, $\mathrm{df}=6, \mathrm{p}<.001)$. Again, only the latency results are reported.

Subsequent Mann-Whitney $U$ tests indicated that at the 1-day retention interval, the animals tested at $33^{\circ}-35^{\circ} \mathrm{C}\left(\mathrm{R}-1-34^{\circ} \mathrm{C}\right)$ displayed severe memory loss as their latencies are comparable to the amnesic 


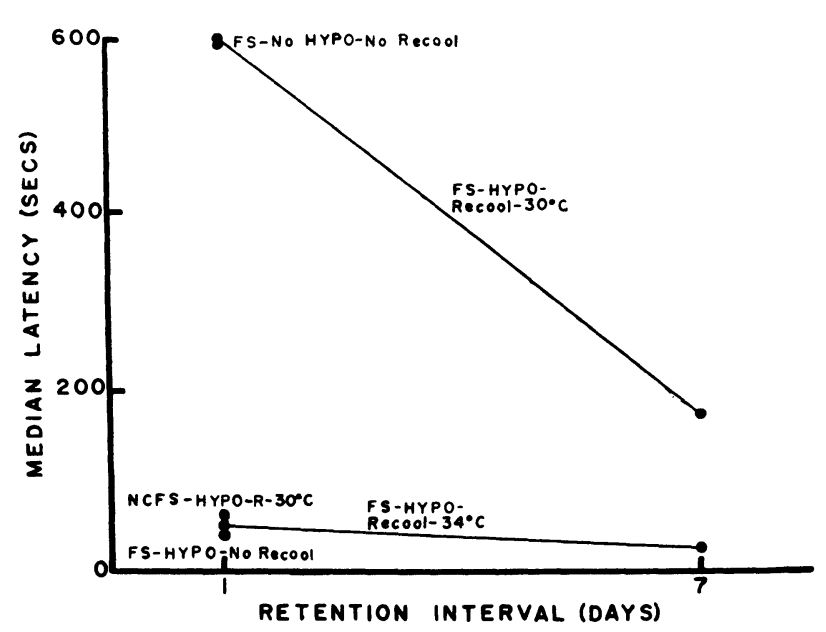

Figure 2. Median test latency at two levels of recooling as a function of retention interval.

group not recooled and to animals never trained (Us $>30$, ps $>.10$ ). In contrast, the group tested at $29^{\circ}-31^{\circ} \mathrm{C}\left(\mathrm{R}-1-30^{\circ} \mathrm{C}\right)$ displayed memory comparable to the retention controls $(U=30, n / n=9 / 8$, $\mathrm{p}>$.10). It appears that recooling after a 1-day retention interval alleviates the memory deficit typically evidenced at that time interval $\left(\mathrm{R}-1-30^{\circ} \mathrm{C}\right.$ : FS-HYPO-No Recool, $U=21, n / n=9 / 10$, $\mathrm{p}<.05$, one-tailed), but only if body temperature is sufficiently low at time of testing $\left(\mathrm{R}-1-30^{\circ} \mathrm{C}: \mathrm{R}-1-\right.$ $34^{\circ} \mathrm{C}, \mathrm{U}=19, \mathrm{n} / \mathrm{n}=9 / 9, \mathrm{p} \leqslant .05$, one-tailed).

A parallel effect was noted at the 7-day retention interval. The reactivation group tested at $33^{\circ}-35^{\circ} \mathrm{C}$ (R-7-34 $\left.{ }^{\circ} \mathrm{C}\right)$ displayed minimal retention, statistically indistinguishable from the comparable 1-day group $(\mathrm{U}=25, \mathrm{n} / \mathrm{n}=8 / 9, \mathrm{p}>.10)$. Furthermore, the 7-day group tested at approximately $30^{\circ} \mathrm{C}$ displayed significantly greater retention than the comparable group tested at slightly warmer body temperature (R-7-30 $\left.{ }^{\circ} \mathrm{C}: \mathrm{R}-7-34^{\circ} \mathrm{C}, \mathrm{U}=7, \mathrm{n} / \mathrm{n}=7 \prime^{\prime} 8, \mathrm{p}<.014\right)$. Thus, a recooling treatment may remain a sufficient cue to serve in the reactivation of a memory trace when delayed for a 7-day retention interval. Complete assessment of the magnitude of this memory recovery after a 7-day retention interval was not possible as no retention control animals were tested at that interval.

The long latencies in reactivated groups tested at cold body temperatures cannot be attributed to debilitating effects of the recooling treatment. The performance control group tested at $29^{\circ}-31^{\circ} \mathrm{C}$ exhibited cross-through latencies significantly faster than the experimental animals tested at similar temperatures $(\mathrm{U}=27.5, \mathrm{n} / \mathrm{n}=8 / 16, \mathrm{p}<.05)$.

\section{GENERAL DISCUSSION}

Previous studies on hypothermia-induced RA have found retention for short intervals following administration of the amnesic agent (Hinderliter, Webster, \& Riccio, 1975; Misanin, Nagy, Keiser, \& Bowen, 1971). The present data provide additional support for the short-term retention, and further suggest that hypothermia-induced RA requires a rather long interval of up to $16 \mathrm{~h}$ to be fully manifest. It is also clear that the magnitude of RA cannot be indexed by body temperature at time of testing, as mean body temperatures were normal at every session.

The results of the second experiment agree with the growing literature on experimentally induced alleviation of memory deficits (Miller \& Springer, 1973; Spear, 1973). The present data replicated and extended to 7 days the previous observation that memory recovery after hypothermia-induced RA can be facilitated with a recooling treatment (Hinderliter et al., 1975). This finding is consistent with the Miller and Springer (1972a) study, where the reactivation effect was independent of the interval between training and reminder NCFS through a range of $2 \mathrm{~h}$ to 2 weeks. The effectiveness of a recooling treatment is most easily demonstrated when testing occurs at cold, but not cool or normal, body temperature. This extends and clarifies the previous report by Hinderliter et al. of memory recovery at short, but not long, recooling-test intervals. The effectiveness of both recooling and NCFS treatments suggests that long-term storage has not been disrupted by the amnesic agents and therefore does not support either traditional or "dual trace" (McGaugh \& Dawson, 1971) consolidation theory. The latter view assumes that the amnesic agent prevents long-term, but not short-term, memory storage. Together, the results of Experiments 1 and 2 are consistent with the emphasis of retrieval theory; RA interferes with the accessibility to, and not the storage of, memory (Lewis, 1969, 1976).

The present study highlights the intriguing, yet unexplained, role of body temperature in the alleviation, but not in the delayed onset, of RA. While Experiment 1 found good retention of a PA task after return of body temperature to normal levels following a hypothermia treatment, paradoxically, Experiment 2 suggested a temperature-dependent recovery of memory. One potential difference between the onset of RA and reactivation is that in the former the more severe treatment produces more extreme and/or more widespread hormonal and other bodily changes which persist beyond the recovery of normal temperature. Retention may be attenuated or enhanced, depending upon the number 
of, and degree of, physiological processes and mechanisms disrupted. Another possibility is that recovery in all respects is more rapid after a second hypothermia treatment, and thus, coincidentally, temperature appears to be an important index. In other words, after a second treatment, the other indices correspond more closely to temperature recovery. A study incorporating a recooling treatment as severe as the original amnesic treatment may substantiate these speculations.

Perhaps the most parsimonious account of both present and past data employing hypothermia may be given in terms of contextual cues (Hinderliter et al., 1975; Spear, 1973; Tulving, 1974) and a hierarchy of cue utilization. While the "cold cues" may serve as a potent cue for retrieval of memory in an amnesic animal, they may not be necessary for retention shortly after hypothermia, because a host of other situational cues associated with the PA training experience are still available. The assumption of a hierarchy of cue utilization is useful to explain the effectiveness of the cold cues in the reactivation paradigm where the other situational cues of training have dissipated. This interpretation may also explain the data which demonstrated that rewarming immediately after hypothermia treatment may prevent RA (Wetsel, Riccio, \& Hinderliter, 1976). The rewarming treatment may slow or halt the disruption of the underlying physiological mechanisms that hypothermia initiates and therefore no behavioral evidence of RA would be evident $24 \mathrm{~h}$ after immediate rewarming. It will now be of interest to determine whether a rewarming following a reactivation treatment also abolishes the cues which would otherwise permit memory retrieval.

\section{REFERENCES}

Campbell, B. A., \& Teghtsoonian, R. Electrical and behavioral effects of different types of shock stimuli on the rat. Journal of Comparative and Physiological Psychology, 1958, 51, 185-192.
Duncan, C. P. The retroactive effect of electroshock on learning. Journal of Comparative and Physiological Psychology, 1949, 42, 32-44.

Geller, A., \& JARVIK, M. E. The time relations of ECS induced amnesia. Psychonomic Science, 1968, 12, 169-170.

Glickman, S. E. Perseverative neural processes and consolidation of the memory trace. Psychological Bulletin, 1961, 58, 218-233.

Hinderliter, C. F., Webster, T., \& Riccio, D. C. Amnesia induced by hypothermia as a function of treatment-test interval and recooling in rats. Animal Learning \& Behavior, 1975, 3, 257-263.

LewIs, D. L. Sources of experimental amnesia. Psychological Review, 1969, 76, 461-472.

LEwIS, D. J. A cognitive approach to experimental amnesia. American Journal of Psychology, 1976, 89, 51-80.

McGaUGH, J. L. Time-dependent processes in memory storage. Science, 1966, 153, 1351-1358.

McGaugh, J. L., \& Dawson, R. G. Modification of memory storage processes. Behavioral Science, 1971, 16, 45-63.

McGaugh, J. L., \& Landfield, P. W. Delayed development of amnesia following electroconvulsive shock. Physiology and Behavior, 1970, 5, 1109-1113.

Miller, R. R., \& Springer, A. D. Temporal course of amnesia in rats after electroconvulsive shock. Physiology and Behavior, $1971,6,229-233$.

MilleR, R. R., \& SPRINGER, A. D. Induced recovery of memory in rats following electroconvulsive shock. Physiology and Behavior, 1972, 8, 645-651.

Miller, R. R., \& Springer, A. D. Amnesia, consolidation, and retrieval. Psychological Review, 1973, 80, 69-79.

Misanin, J. R., Nagy, M., Keiser, E. F., \& Bowen, W. Emergence of long-term memory in the neonatal rat. Journal of Comparative and Physiological Psychology, 1971, 77, 188-199.

Riccio, D. C., \& Stikes, E. R. Persistent but modifiable retrograde amnesia produced by hypothermia. Physiology and Behavior, 1969, 4, 649-652.

SPEAR, N. E. Retrieval of memory in animals. Psychological Review, 1973, 80, 163-194.

Tulving, E. Cue-dependent forgetting. American Scientist, 1974, 62, 74-82.

Wetsel, W. C., Riccio, D. C., \& Hinderliter, C. F. Effects of artificial rewarming upon hypothermia-induced retrograde amnesia. Physiological Psychology, 1976, 4, 201-206.

Zerbolio. D. J., JR. Retrograde amnesia: The first post-trial hour. Communications in Behavioral Biology, 1971, 6, 25-29.

(Received for publication October 7, 1977; revision accepted November 22, 1977.) 